\title{
Mechanisms of Color Production in a Highly Variable Shield-Back Stinkbug, Tectocoris diopthalmus (Heteroptera: Scutelleridae), and Why It Matters
}

\author{
Scott A. Fabricant ${ }^{1 *}$, Darrell J. Kemp ${ }^{1}$, Jan Krajiček ${ }^{2}$, Zuzana Bosáková ${ }^{2}$, Marie E. Herberstein ${ }^{1}$ \\ 1 Department of Biological Sciences, Macquarie University, North Ryde, New South Wales, Australia, 2 Department of Analytical Chemistry, Charles University in Prague, \\ Prague, Czech Republic
}

\begin{abstract}
Theory suggests that aposematism, specifically the learned avoidance of unprofitable prey via memorable color patterns, should result in selection for pattern uniformity. However, many examples to the contrary are seen in nature. Conversely, honest sexual signals are likely to exhibit greater variation because they reflect underlying variation in mate quality. Here we aim to characterize and quantify the mechanistic causes of color in Tectocoris diopthalmus to shed light on the costs of color production, and thus the potential information content of its color signals. We use Tectocoris diopthalmus because it is a weakly-defended stinkbug, and presents elements that have classically been studied in the context of aposematism (red coloring), and sexual selection (sexual dichromatism and iridescent coloring). Pigment analysis reveals that variation in orange coloration is due to the amount of erythropterin pigment, stored in intracellular granules. This pigment is common in Heteroptera, and as an endogenously produced excretory byproduct is unlikely to reflect mate quality or variation in unprofitability of the bug. Electron microscopy reveals the iridescent patches are caused by an epicuticular multilayer reflector, and the hue and patch size are directly related to the layer widths and extent of coverage of this layering. Furthermore, we identified melanin as an essential component of the multilayer reflector system; therefore, the quality of the iridescent patches may be affected by aspects of rearing environment and immunocompetence. We posit that $T$. diopthalmus has co-opted the melanic patches of a 'typical' red and black aposematic signal, transforming it into a complex and variable iridescent signal that may enhance its capacity to display individual quality.
\end{abstract}

Citation: Fabricant SA, Kemp DJ, Krajíček J, Bosáková Z, Herberstein ME (2013) Mechanisms of Color Production in a Highly Variable Shield-Back Stinkbug, Tectocoris diopthalmus (Heteroptera: Scutelleridae), and Why It Matters. PLoS ONE 8(5): e64082. doi:10.1371/journal.pone.0064082

Editor: Kevin McGraw, Arizona State University, United States of America

Received February 7, 2013; Accepted April 11, 2013; Published May 7, 2013

Copyright: (c) 2013 Fabricant et al. This is an open-access article distributed under the terms of the Creative Commons Attribution License, which permits unrestricted use, distribution, and reproduction in any medium, provided the original author and source are credited.

Funding: Funding was provided by a Macquarie University Research Excellence Scholarship, as well as additional financial support from the Grant Agency of the Czech Republic, P505/11/1459, the Ministry of Education of the Czech Republic, MSM0021620857 and Charles University SVV (Specifický Vysokoškolský Výzkum, or Specific University Research) student grant. The funders had no role in study design, data collection and analysis, decision to publish, or preparation of the manuscript.

Competing Interests: The authors have declared that no competing interests exist.

*E-mail: scott.fabricant@mq.edu.au

\section{Introduction}

Aposematism is the phenomenon wherein defended prey advertise unprofitability through conspicuous signals. Often these take the form of bright 'warning colors', as it is theorized that conspicuous coloration aids predator recognition and memory [1]. Generally, the 'typical' aposematic patterns of insects are red or yellow coloration with black markings [2] [3].

Theory suggests that aposematic patterns should be under strong frequency-dependent selection by predators to be monomorphic [4] [5], and/or strong directional selection for conspicuousness [6] [7]. However, examples of species with variable patterns or other deviations from theoretical predictions are common [3]. Recent theoretical treatments have addressed possible causes of intermediate aposematism and intraspecies variation in pattern, via such mechanisms as predator community structure [8], or variation in prey defense levels [9]. Notably, Blount's et al. [10] model of intraspecific variation explicitly explores color production mechanisms as drivers of variation, through the vehicle of pigments acting as antioxidants to defend against autotoxicity. Recent empirical studies have also demon- strated possible trade-offs between warning signal quality and physiological traits such as toxin excretion costs [11] and pathogen resistance [12], It is hence possible than the mechanisms of aposematic signals themselves, and related physiological traits, are contributing to variation.

Another potential factor contributing to intraspecific variation in aposematic signals is the interaction between selection by predation and sexual selection [13]. Honest sexual signals are likely to exhibit variation because they reflect underlying variation in mate quality [14], and sexual selection may act in opposition to predator selection for uniformity [15]. Identifying the proximate causes of color production can reveal potential costs and constraints, and suggest aspects of the information content of signals. For example, structural coloration is produced by submicron-level organization creating constructive interference with light [16]. Quality and regularity of the ultrastructure can affect its visual qualities [17]. Structural colors can be sensitive to perturbations during development, so poor-quality patches may indicate developmental stress [18], or poor genetic regulation [19]. Pigments are light-absorbing molecules that do not necessarily require fine-scale organization, but can also be sensitive to 
developmental stress [20], and may reveal different information to structural color [21]. Two well-studied examples are carotenoids, which produce red or yellow coloration and are involved in antioxidant defense [22], and melanin, which produces brown and black coloration and is an integral component of the insect encapsulation response to parasites [23]. Some pigments can only be sequestered from diet, while others may be costly to manufacture de novo, so different types of pigment can relate to different aspects of mate quality [24]. Variation in color patterns may therefore be informative to mate choice and may be under strong sexual selection and/or physiological constraints, counteracting predator selection for uniformity of aposematic signals.

In addition to selection by predators, sexual selection, and physiological trade-offs, elements of color patterns may be sensitive to environmental factors. Examples include temperature-induced melanization [25] [26], and effects of food limitation on carotenoid intake [22] or nitrogen intake necessary for pteridine synthesis [27] [28]. Such 'direct' costs may induce variation irrespective of the 'indirect' costs of sexual or predator selection. Therefore, we suggest that a 'bottom-up' approach of investigating color production mechanisms is a productive avenue of research for identifying the potential selective pressures, trade-offs, and constraints that may be shaping color patterns.

In this study, we characterize and quantify the color production mechanisms of Tectocoris diopthalmus (Heteroptera: Scutelleridae), the Hibiscus Harlequin Bug. This large, charismatic stinkbug is widely distributed along the eastern and northern coasts of Australia and nearby Pacific islands [29]. Its defensive secretions have been identified [30], and these chemicals are known to be aversive to some predators, including birds [31] and praying mantids [32]. Rather than employing the more 'typical' aposematic color scheme of red or yellow with black markings, $T$. diopthalmus display a matte red-orange background with bright metallic blue-green iridescent patches. Because of their iridescence (the phenomenon of observed hue changing with viewing angle), these patches are likely to be produced by structural coloration. Both pattern elements are highly variable; the base color varies from a saturated red to very pale orange, while the iridescent patches range in hue from violet to green, and range in size from almost covering the dorsal surface to being entirely absent (figure 1). The species is sexually dichromatic, with males more likely to have large iridescent patches and deeper red coloration [33]. There are broad latitudinal [34] and seasonal [33] patterns in variation, as well as variation between individuals in one population at a given time. The use of iridescence in aposematic patterns is somewhat surprising, because the hue shifts with viewing angle introduce even further variability to the pattern (but see [35] and [36] for other potential cases of iridescent aposematic signals). The prominent use of both putatively structural and pigmentary color make $T$. diopthalmus an ideal candidate for detailed investigation. Furthermore, $T$. diopthalmus is sympatric over part of its range with Cantao parentum, a similar-sized scutellerid with similar life-history that displays a more 'conventional' red with black spotted pattern [29], which raises the question of why $\mathcal{T}$. diopthalmus in particular features iridescent patches.

Our aim is to use histological and chemical methods to examine the color production mechanisms of $T$. diopthalmus, and thus the proximate causes of color variation in a putatively aposematic, sexually dimorphic bug. Characterizing the mechanisms will also facilitate identifying potential physiological costs and help elucidate information content of the various signal components. Furthermore, identification of color mechanisms will highlight specific avenues for future research into factors maintaining color variation, and is an important step for exploring the paradox of intraspecific variation in aposematism.

\section{Materials and Methods}

Adult male and female Hibiscus Harlequin Bugs (Tectocoris diopthalmus) were collected off Norfolk Island Hibiscus (Lagunaria patersonia) trees planted on streets near the beaches of Narrabeen and Dee Why, New South Wales, Australia. No specific permissions were required to collect insects from local councilplanted trees, and this species is not considered threatened or otherwise protected under law. Bugs were maintained in the lab on potted Beach Hibiscus (Hibiscus tileaceus) plants supplemented with seed pod cuttings from Norfolk Island Hibiscus and Native Rosella (Hibiscus heterophyllus) plants. Individuals were killed with ethyl acetate fumes, as freezing appeared to alter the appearance and likely the ultrastructure of the iridescent patches.

To quantify the color of the iridescent and orange patches, reflectance spectra of bug integument (12 males, 10 females) were obtained using an Ocean Optics USB 4000 Spectrophotometer with a fiber optic probe positioned at a $45^{\circ}$ angle to the incident light source. The light source was an Ocean Optics PX-2 Pulsed Xenon lamp with an optic fiber positioned above the specimen. Insects were pinned to a three-axis freely rotating stage and rotated to positions of maximum brightness reflected. Samples were measured between 300 and $700 \mathrm{~nm}$. Polytetraethylene (Teflon ${ }^{\mathrm{TM}}$ ) tape was used as the white standard, which provides over $97 \%$ reflectivity over the spectral range of interest [37]. To test for linearly polarized reflectance, specimens were viewed through a Hoya linear polarizer while rotating it; to test for circularly polarized light, specimens were viewed through a Hoya linear polarizer rotated behind a quarter-wave plate [38].

Electron microscopy was used to image the cuticular ultrastructure responsible for creating the iridescent patches. One representative male and one female were imaged by Scanning Electron Microscopy (SEM). Pieces of the scutellum were fixed in a $3 \%$ glutaraldehye solution in phosphate buffer $\mathrm{pH} 7.2$ overnight, dehydrated in a graded ethanol series $(50 \%, 70 \%, 90 \%, 100 \%$, $100 \%$; 15 minutes each step), and dried with an Emitech K850 critical point dryer. The pieces were then mounted on aluminium stubs and sputter coated with gold (approximately $20 \mathrm{~nm}$ thick). Specimens were viewed with a Jeol JSM 6480 scanning electron microscope.

Two males, one female, and one juvenile bug were imaged for Transmission Electron Microscopy (TEM). Pieces of scutellum were fixed in a $3 \%$ glutaraldehyde solution in phosphate buffer pH 7.2 overnight, and post-fixed in a $1 \%$ osmium tetroxide solution for 2 hours, followed by a $2 \%$ uranyl acetate solution for 30 minutes. The samples were dehydrated using a graded ethanol series $(50 \%, 70 \%, 80 \%, 90 \%, 95 \%, 100 \%, 100 \%$; 30 minutes each step), and infiltrated in LR White resin using a resin-ethanol series $(1: 3,1: 2,1: 1,2: 1,3: 1,100 \% \times 2,1.5$ hours each). The final immersion was held under vacuum for 5 hours, before being loaded into molds and polymerized at $70^{\circ} \mathrm{C}$. Semi-thin $(0.7 \mu \mathrm{m})$ and ultra-thin sections $(\sim 70 \mathrm{~nm})$ were cut perpendicular to the dorsal surface using a Reicherts Ultracut S microtome with a diamond knife. Semi-thin sections were viewed with an Olympus BH-2 microscope with Scion GFW-1310C color digital camera. Ultra-thin sections were mounted on copper TEM grids coated with $0.3 \%$ pioloform, and stained with $7.7 \%$ uranyl acetate for 30 minutes, followed by Reynolds lead citrate [39] for 5 minutes. Specimens had a sectioned transversely across the color interface. Sections were imaged with a Philips CM10 transmission electron microscope with Olympus SIS Megaview G2 digital camera. 


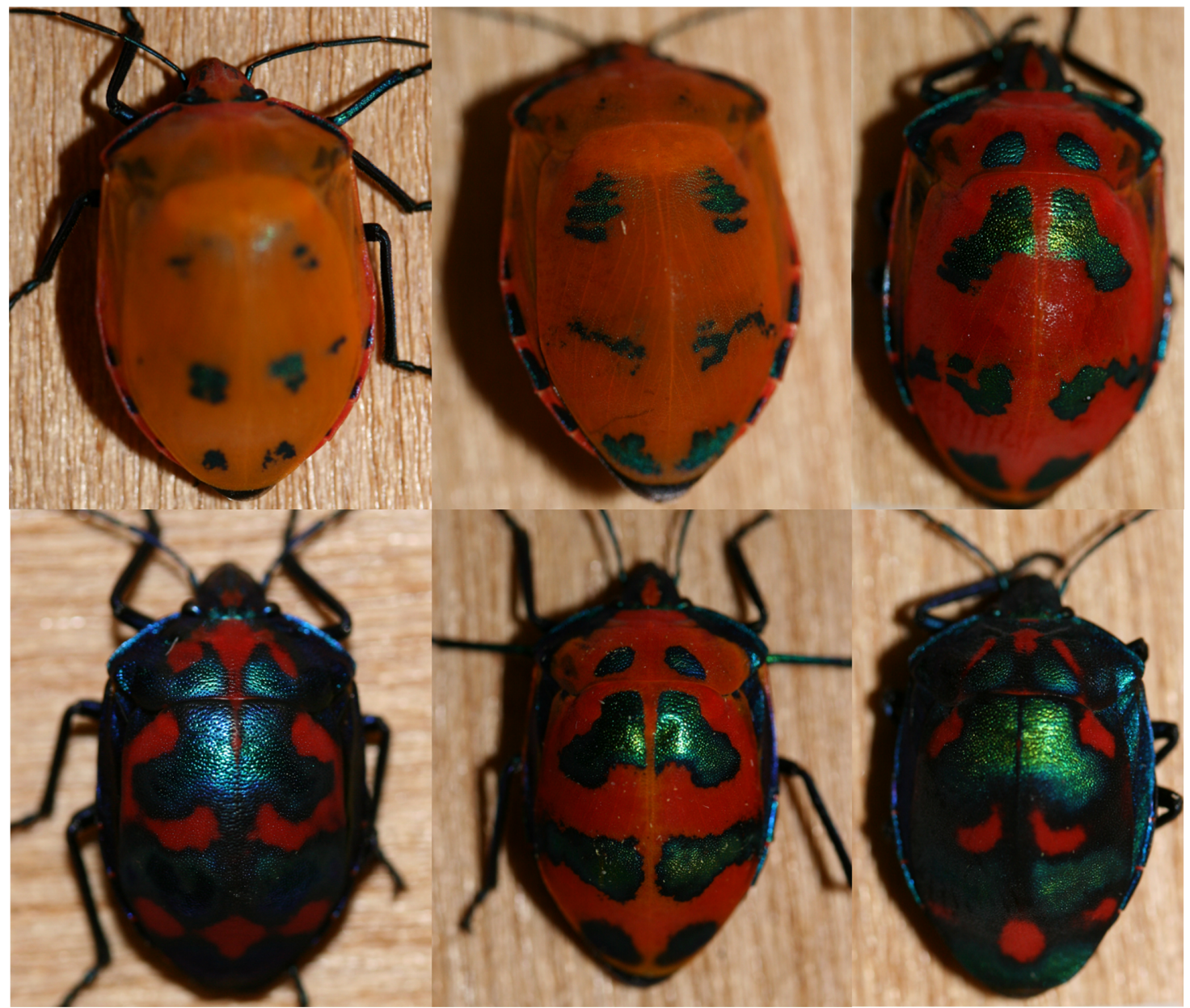

Figure 1. Examples of variation among individual of $T$. diopthalmus. Pictured are six individual $T$. diopthalmus; the top row is females, the bottom row is males, as examples of the variation between individuals in T. diopthalmus. This is not the extent of possible variation, as both males and females are capable of displaying patterns between complete absence and near total coverage of iridescence, and between rich red and virtually white pale orange.

doi:10.1371/journal.pone.0064082.g001

Measurements of layer width were made at six random points along the transverse section using Olympus iTEM 5.1 software.

For preliminary pigment analysis, carotenoid presence was tested using the acidified pyridine method [40]. To distinguish between other candidate pigment classes (melanins, pterins, flavonoids, and ommochromes), a discriminatory extraction test, modified from Lindstedt et al. [41], was used. Pterins and flavonoids are soluble in strong acids and bases, but flavonoids are also soluble in neutral organic solvents such as methanol, while ommochromes are soluble in acidified alcohols [28] [42]. Both intact and crushed-whole bugs were placed in vials of $0.1 \mathrm{M}$ sodium hydroxide, 90\% methanol, or 1:10 hydrochloric acid/ methanol solution, and incubated at room temperature for 24 hours. Insect parts were removed and the extracts were centrifuged at 14,000 RPM for 5 minutes. The supernatants were then measured using a Shimadzu UVmini 1240 UV-Vis Spectrophotometer using quartz cuvettes across a wavelength range of 200 to $800 \mathrm{~nm}$. Absorbance spectra were compared against published spectra [43]. Both intact bugs and extracted supernatants were observed under short-wave $(254 \mathrm{~nm})$ and longwave $(366 \mathrm{~nm})$ ultraviolet light to visually inspect for the presence of fluorescence, as pterins and flavonoids fluoresce under UV light while carotenoids, ommochromes, and melanins do not [28] [42].
Based on the preliminary results of pigment analysis, we focused our identification efforts on pterin pigments. For the separation and identification of pterins potentially present in the integuments of $T$. diopthalmus, a capillary electrophoretic method (CE) was developed. The separation system was modified from Han et al. [44]. The CE measurements with UV detection were carried out on an Agilent Technologies $\mathrm{HP}^{3 \mathrm{D}} \mathrm{CE}$ system with built-in diode array detector operated at $250 \mathrm{~nm}$. CE analyses were conducted in an uncoated fused-silica capillary (CACO) total length $70 \mathrm{~cm}$, $55 \mathrm{~cm}$ to the detector, inner diameter $50 \mu \mathrm{m}$, thermostated at $30^{\circ} \mathrm{C}$. Background electrolyte (BGE) contained a mixture of $100 \mathrm{mmol} / \mathrm{L}$ boric acid, $100 \mathrm{mmol} / \mathrm{L}$ tris(hydroxymethyl)aminomethane (TRIS), $\mathrm{pH} 9,0$, and $2 \mathrm{mmol} / \mathrm{L}$ ethylenediaminetetraacetic acid disodium salt dihydrate $\left(\mathrm{Na}_{2} \mathrm{EDTA}\right)$. Samples were injected electrokinetically at $20 \mathrm{kV}$ for 10 seconds, and the applied separation voltage was $20 \mathrm{kV}$. Pterin standards included biopterin, isoxanthopterin, leucopterin, neopterin, xanthopterin, and erythopterin (all from Sigma Aldrich except erythropterin provided by R. Rutowski). Stock solutions of the individual standards were prepared by dissolving the compounds in dimethyl sulfoxide at a concentration of $0.1 \mathrm{mg} / \mathrm{mL}$ and were kept in dark at $4^{\circ} \mathrm{C}$. Working standard solutions were prepared by diluting the stock solutions with BGE to a concentration of $0.025 \mathrm{mg} / \mathrm{ml}$. Identi- 
fication was carried out by spiking samples with pure standard solutions.

Dried integuments were used in the CE analysis. Three bugs of each color morph ('red' vs 'orange', as judged visually by experimenter) were used in each extraction, to minimize the effects of individual variation. Integuments were weighed $(\sim 6 \mathrm{mg}$ per red extract and $\sim 8 \mathrm{mg}$ per orange extract) and put in a vial with $0.5 \mathrm{~mL}$ dimethyl sulfoxide to be incubated in the dark at room temperature for 98 hours. The extract was centrifuged at 13,000 RPM for 10 minutes. The supernatant was then diluted $4 \times$ with BGE before being used for CE analysis. Three extracts of red form and orange form were prepared, for a total of nine individuals sampled per morph.

To test whether the otherwise-insoluble iridescence is dependent on melanin for its optical properties, photographs and spectra of 5 sample bugs were taken before being immersed in 20\% hydrogen peroxide for 24 hours, after which the bugs were washed with water, photographed and measured spectrally (see above) again. Hydrogen peroxide breaks down melanin [45], and degrade melanin-containing layers in the ultrastructure in situ, decreasing both peak reflectance wavelength and brightness [46].

\section{Results}

Selected example spectra for the iridescent and orange patches can be seen in Figure 2. The iridescent patches show a sharp peak, which, in the individuals sampled, can range between 480 and 570 nanometers, while the orange base shows a monotonic increase beginning at between 512 and 590 nanometers, leveling off by 700 nanometers. In this study male scutellum iridescent patches are on average more blue-shifted (average peak of $520 \pm 24 \mathrm{~nm}$ versus $542 \pm 17 \mathrm{~nm}$ for females), while the male's orange patches are more red-shifted, reflecting on average light of $580 \pm 14 \mathrm{~nm}$ or greater (versus $538 \pm 24 \mathrm{~nm}$ or greater for females), creating greater chromatic contrast. No polarized reflectance, either linear or circular, was detected at normal light incidence and viewing angle in either sex.

In the differential solubility test, an orange-colored pigment was soluble in $0.1 \mathrm{M} \mathrm{NaOH}$ and acidified methanol, but not neutral methanol (Table 1). The absorbance peak in acidified methanol was at $430 \mathrm{~nm}$, with a trough at $380 \mathrm{~nm}$, closely approximating published spectra for erythropterin [43]. Extracts could not be obtained from intact bugs, but only from ground specimens. Unstained semi-thin sections of cuticle reveal red granules inside epidermal cells underneath unpigmented cuticle (Figure 3). Both pigment extracts and the venters of intact bugs fluoresce under ultraviolet light (Table 1).

For confirmation and specification of pterin derivative(s) responsible for the coloration, organic extracts of integuments from orange and red morphs of $T$. diopthalmus were analyzed by capillary electrophoresis (CE). The results obtained from one extraction of 'red' and 'orange' forms are shown in Figure 4. Four peaks were identified in both morphs. Peak 1 , the negative peak, is due to dimethyl sulfoxide in the injected sample. Peaks 2 and 3 correspond to isoxanthopterin and leucopterin respectively, which are colorless in visible wavelengths but absorb ultraviolet light. Peak 4 is erythropterin, a red-reflecting pigment which absorbs shorter wavelengths. Both morphs also contain small amounts of colorless biopterin [unlabeled]. Qualitatively, electrophoreograms obtained for a given color morph were nearly identical. The key color difference identified between red and orange morphs is the greater amount of erythropterin present in the red morph (mean peak area $4.23 \pm 0.59$ milliabsorption units*seconds, from $6 \mathrm{mg}$ of integument) versus the orange morph (mean peak area $2.87 \pm 0.15$

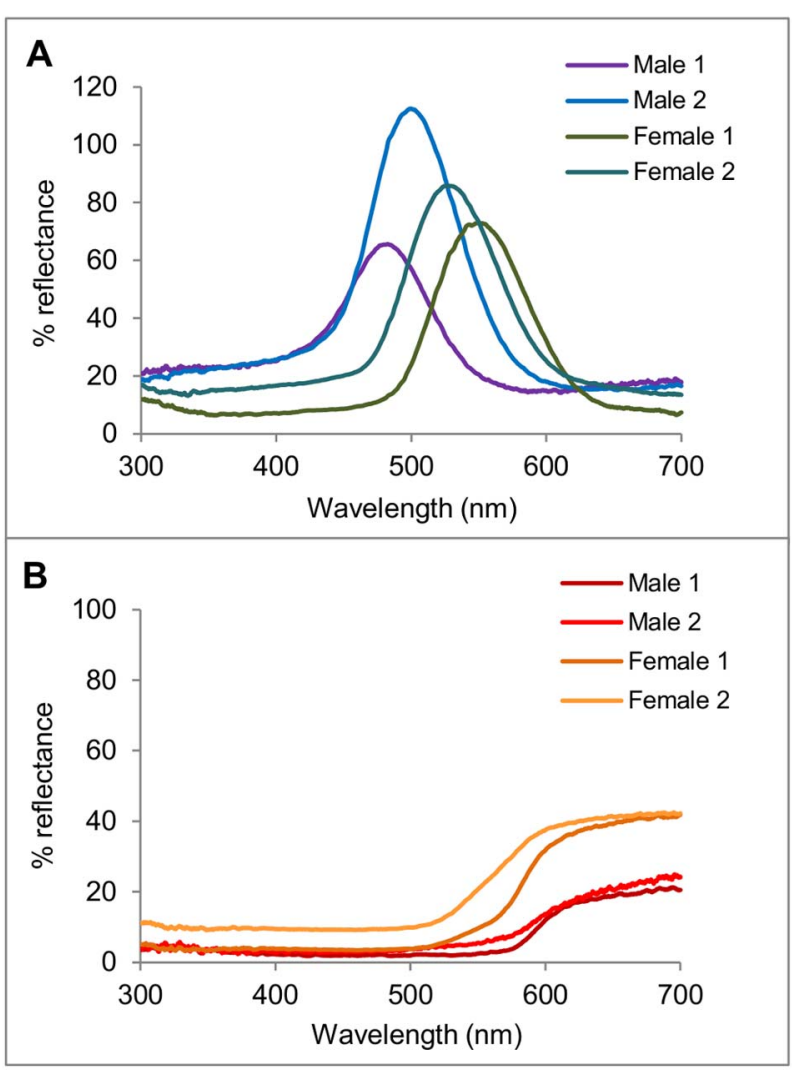

Figure 2. Example reflectance spectra of $T$. diopthalmus color patches. The spectral reflectance curves of the color patches of four individuals (two males, two females) are shown here. Curves from iridescent dorsal patches are shown in A, while the curves from the dorsal orange patches of the same individual are shown in B. Precent reflectance is against a Teflon white standard. doi:10.1371/journal.pone.0064082.g002

milliabsorption units*seconds, from $8 \mathrm{mg}$ of integument). Xanthopterin, a common reddish-orange pigment, was not found in any tested samples.

Scanning electron microscopy revealed that the dorsal surface is covered by microtubules of uneven size but roughly even spacing. These microtubules can be found uniformly over the scutellum of both males and females regardless of underlying color (Figure 5). Transmission electron microscopy revealed no microstructure in the cuticle of the orange patches.

TEM imaging did however reveal ultrastructure to the iridescent patches compromising a multilayer system in the epicuticle (Figure 6). The structure consists of alternating layers of 'dark' (electron-dense) and 'light' (electron-lucent) material, bordered on the outside by a thinner semi-lucent layer, and underlaid by a thick layer of pigmented exocuticle (Figure 7). There are between 5 and 9 layers, on average 7 , of each layer type. The average width of the layers is between 60 and 90 nanometers, depending on the individual measured (Table 2). At the base of the multilayer system, and at the interface between the iridescence patches and the black border regions (not shown), the 'light' layers degenerate, and the 'dark' layers seamlessly merge with the underlying pigmented layer. The underlying layer appears as a thick brown line under light microscopy. For a comparison of measured and predicted peak wavelengths of the iridescent patches in the individuals examined, see Table 2. 


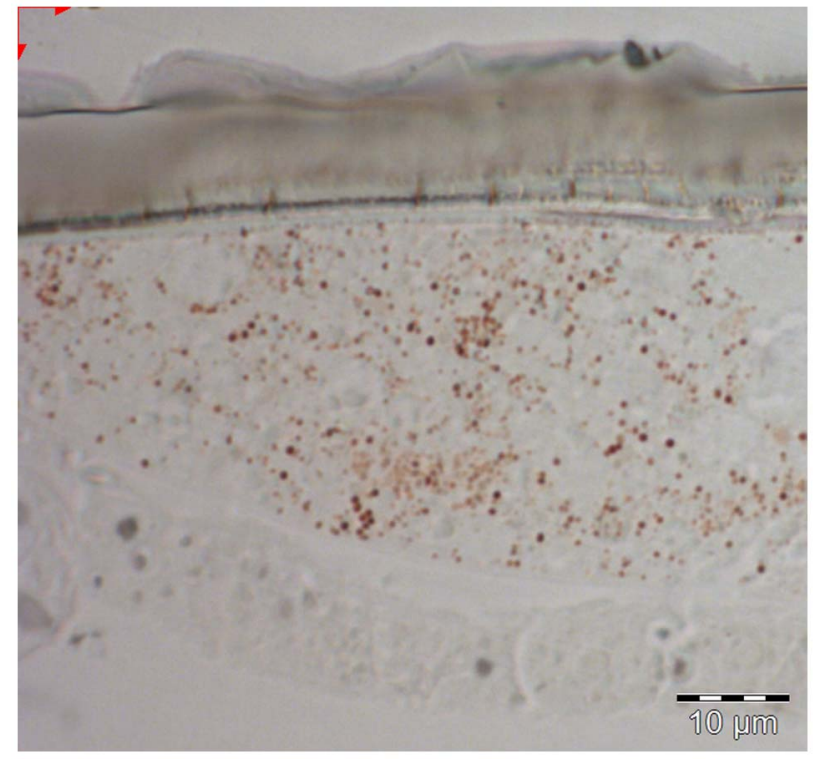

Figure 3. Light microscopy image of epidermal cell in $T$. diopthalmus. Unstained thin section of an epidermal cell underneath cuticle in the ventral surface of $T$. diopthalmus. The small red granules near the distal end are believed to be pigment granules containing pterins.

doi:10.1371/journal.pone.0064082.g003

For the bugs soaked in hydrogen peroxide, the peak reflectance of the iridescent spots was shifted to a shorter wavelength, the peak brightness was dramatically reduced, and the broadband reflectance was increased, with a monotonic rise at longer wavelengths (Figure 8). This is indicative of both a marked reduction in the optical thickness of the layers and leeching of the underlying pigment.

\section{Discussion}

Identification of color production mechanisms

We identified two major color production mechanisms in Tectocoris diopthalmus, a red-orange pigment and a multilayer reflector structure. The structure exists in the outermost exoskeletal layer, while the pigment is contained in intracellular granules in the epidermis. We identified the pigment as a pterin-based compound due to its fluorescence characteristics and solubility in acidified or basic aqueous or organic solvent (Table 1). The color
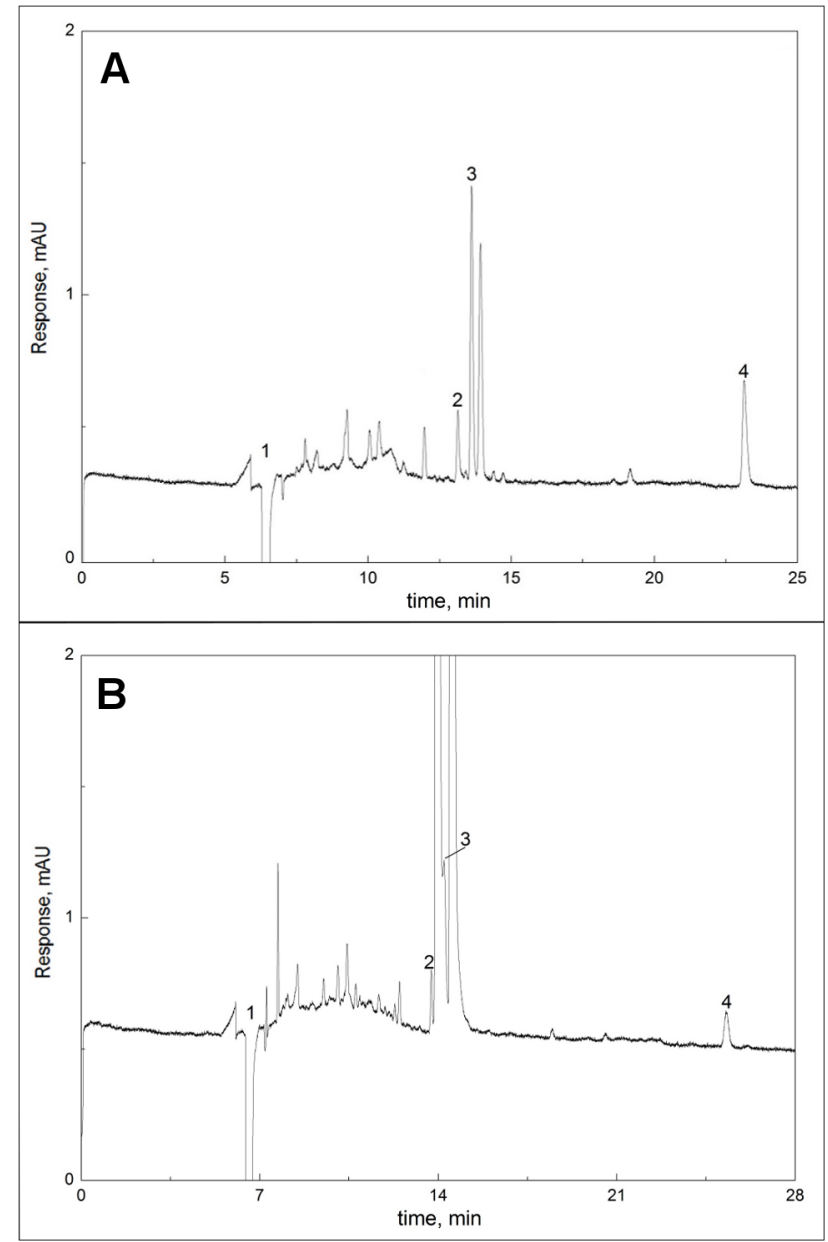

Figure 4. Analysis of pterin-based pigments of $T$. diopthalmus by Capillary Electrophoresis (CE). Capillary Electrophoresis (CE) analysis of red (A) and orange (B) forms of integuments of Tectocoris diopthalmus at $250 \mathrm{~nm}$. Peaks: 1- dimethyl sulfoxide,2- isoxanthopterin, 3-leucopterin, 4-erythropterin. Note the larger erythropterin peak in the red form.

doi:10.1371/journal.pone.0064082.g004

causing pigment has been specifically identified as erythropterin by capillary electrophoresis, and differences in the hue of the redorange coloration can be largely explained by differences in the amount of erythropterin pigment. This result agrees with previous

Table 1. Discriminatory identification of pigment class.

\begin{tabular}{|c|c|c|c|c|c|}
\hline \multirow[b]{2}{*}{ Pigment Class } & \multicolumn{4}{|c|}{ Dissolves in solvent } & \multirow{2}{*}{ Fluoresces in UV } \\
\hline & $\begin{array}{l}\text { Acidified } \\
\text { Pyridine }\end{array}$ & $0.1 \mathrm{M} \mathrm{NaOH}$ & 90\% Methanol & 10:1 Methanol/HCl & \\
\hline Carotenoids & $\mathrm{x}$ & & & & \\
\hline Pterins & & $\mathrm{x}$ & & $\mathrm{x}$ & $\mathrm{x}$ \\
\hline Flavinoids & & $\mathrm{x}$ & $\mathrm{x}$ & $\mathrm{x}$ & $\mathrm{x}$ \\
\hline Ommochromes & & & & $\mathrm{x}$ & \\
\hline T. diopthalmus extract & & $\mathrm{x}$ & & $\mathrm{x}$ & $\mathrm{x}$ \\
\hline
\end{tabular}




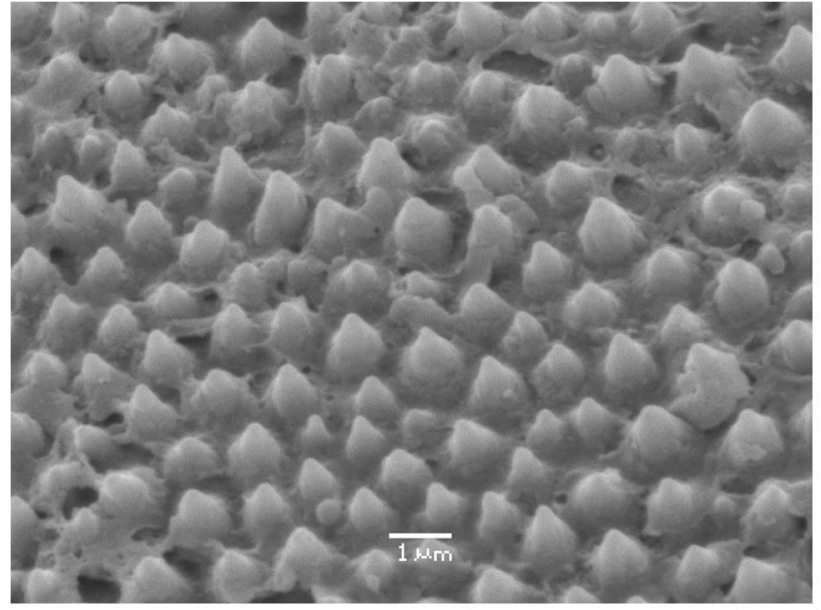

Figure 5. Scanning Electron Microscopy (SEM) image of scutellum surface. SEM imaging shows conical tubercles of varying dimensions covering the surface of the scutellum. These protrusions can be found on both males and females and overlying both iridescent and orange patches.

doi:10.1371/journal.pone.0064082.g005

studies that have identified erythopterin as a major red or orange pigment in heteropterans [47] [48] [49] [50].

The iridescent blue-green coloration is produced by a multilayer reflector in the epicuticle, identifiable in transmission electron micrographs (TEM). Both the structure and results of hydrogen peroxide bleaching closely match the results of Schultz and Rankin [46], thus the Harlequin Bug and Cicindela tiger beetles have likely evolved a convergent system. We therefore posit that the multilayer structure in $T$. diopthalmus is also is composed of alternating layers of melanin-laced and melanin-free protein matrix, overlaying a melanized exocuticle base [46]. These iridescent patches could be an elaboration evolved directly from melanic patches in a more 'typically aposematic' red and black ancestor, perhaps in shared ancestry with Cantao, but this hypothesis requires phylogenetic analysis for further investigation.

The ultrastructure of the epicuticular reflector appears similar to those found in other non-aposematically colored scutellerids [51] [52], as well as cicindelid tiger beetles [53], buprestid jewel beetles [54], and calopterygid damselflies [55]. This is structurally distinct from the rotated helicoidal rotated exocuticle found in scarab reflectors [16], as well as the epicuticular reflector in wasps [56]. The function of iridescence in these animals is often unknown, though it is believed to aid crypsis in Cincindela oregona tiger beetles [57] while functioning as a sexual trait, as an indicator of male condition, in male Calopteryx maculata damselflies [55].

The predicted peak reflectance of the multilayer system can be calculated using Snell's Law, $\lambda_{\max }=2\left(n_{1} d_{1}+n_{2} d_{2}\right)$ wherein the peak reflectance $\left(\lambda_{\max }\right)$ is dependent on the refractive index $(n)$ and thickness (d) of each layer type. Based on measurements of peak reflectance and layer widths, the average refractive index is estimated to be 1.78. Durrer and Villiger [58] estimated the average refractive index of a melanin-based epicuticular reflector to be 1.75 , with the melanic layers having a refractive index of 2.0 and nonmelanic layers having an index of 1.5. This estimate has been used successfully by Schultz and Rankin [46] and Fitzstephens and Getty [55] to predict the peak reflectance of multilayer systems. More recent studies by Noyes et al. [59] and Stavenga et al. [54] place the estimate for melanic layers lower, at between 1.6 and 1.7. Using these lower estimates results in a predicted peak wavelength far lower than the value we measured. We therefore utilize the higher

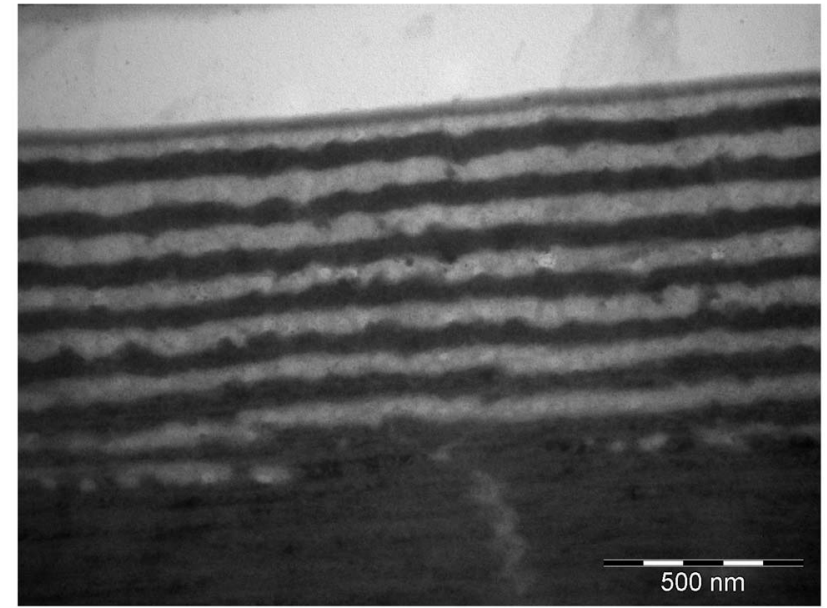

Figure 6. Transmission Electron Micrograph (TEM) of the multilayer reflector. TEM image of the multilayer reflector in $T$. diopthalmus (from sample 2 in table 2). Note the bottommost thin 'dark' layer appears contiguous with the underlying thick dark layer where the separating 'light' layer is disrupted.

doi:10.1371/journal.pone.0064082.g006

value of 2.0 as the refractive index of our electron-dense layer, and consequently 1.56 for our electron-lucent layer. However, we acknowledge the limitations of our analysis and do not intend to make broad claims as to the optical nature of ultrastructural components. Furthermore, diverse claims of the refractive index of ultrastructure components have been made in other scutellerids, including chitin and water (1.58 and 1.33) in Poecilocoris lewisi [51], and chitin and chitin-air grating (1.56 and 1.4) in Calidea panaethiopica [52]. Therefore there may be great evolutionary lability and diversity in ultrastructural components.

The outer surface of the scutellum in both sexes is uniformly covered by small bumps visible in scanning electron micrographs. These microtubercles appear superficially similar to structures

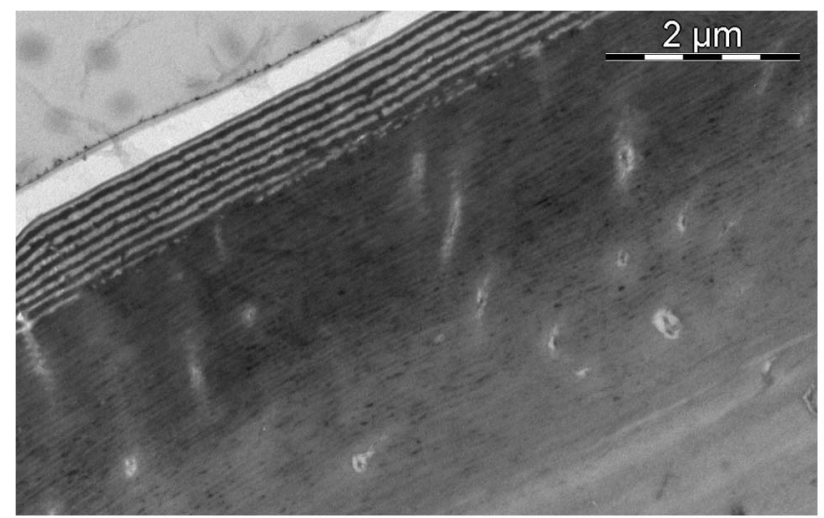

Figure 7. Transmission Electron Micrograph (TEM) of Epicuticle and Exocuticle. Zoomed out version of Figure 6. Three regions of cuticle can be seen. The thin banding in the top-left region is the epicuticle, the outermost layer of cuticle, containing the multilayer reflector. Below that is the exocuticle, with fine helicoidal layering. The upper region of the exocuticle contains an electron-dense pigment which appears brown in unstained thin sections for light microscopy (not pictured). The smoother region in the bottom-right corner is the upper edge of the endocuticle. The apparent thick white layer in the upper-right corner of the micrograph is an artefact due to resin separation from the sample.

doi:10.1371/journal.pone.0064082.g007 
Table 2. Multilayer reflector layer measurements and predicted peak reflectance.

\begin{tabular}{|c|c|c|c|c|c|c|c|}
\hline Sample & Age/Sex & $\begin{array}{l}\text { Measured peak } \\
\text { reflectance }(\mathrm{nm})\end{array}$ & $\begin{array}{l}\text { Number of 'dark' } \\
\text { layers }\end{array}$ & $\begin{array}{l}\text { Width of 'dark' } \\
\text { layers (nm) }\end{array}$ & $\begin{array}{l}\text { Number of 'light' } \\
\text { layers }\end{array}$ & $\begin{array}{l}\text { Width of 'light' } \\
\text { layers (nm) }\end{array}$ & $\begin{array}{l}\text { Predicted peak } \\
\text { reflectance } \\
(\mathrm{nm})\end{array}$ \\
\hline 1 & Male & 462 & $7.2 \pm 1.2$ & $59.2 \pm 5.9$ & $7.3 \pm 0.8$ & $70.3 \pm 4.5$ & $456 \pm 21$ \\
\hline 2 & Male & 532 & $6.8 \pm 1.5$ & $73.1 \pm 5.9$ & $6.5 \pm 1.3$ & $79.4 \pm 6.3$ & $540 \pm 21$ \\
\hline 3 & Female & 538 & $6.2 \pm 1.3$ & $68.6 \pm 9.8$ & $5.8 \pm 0.4$ & $90.6 \pm 5.9$ & $557 \pm 34$ \\
\hline 4 & Juvenile & 463 & $4.8 \pm 0.4$ & $60.9 \pm 4.6$ & $5.2 \pm 0.4$ & $64.3 \pm 5.7$ & $444 \pm 19$ \\
\hline
\end{tabular}

Layer widths (and resulting predicted peak reflectance) given are the mean and standard deviation of the average layer width at six points along the section; therefore, standard deviations reflect horizontal regularity rather than vertical. For examples of 'dark' and 'light' layers, see Figure 6.

doi:10.1371/journal.pone.0064082.t002

found in another scutellerid, Poecilocoris lewisi, which produce a diffuse blue reflectance via Mie scattering [51]. Curiously, we see no evidence for a similar effect in reflectance spectra of $T$. diopthalmus (Figure 2), and do not believe the microtubercles function in color production. It may be that these protrusions act as an anti-reflector structure to reduce specular reflectance, but their dimensions are too large to function effectively in this capacity [60]. Alternatively, they may not have any visual function, and act as an anti-wetting structure [60]; further studies are required to elucidate their biological function.

\section{Exploring the implications of identified mechanisms}

The red-orange color is created primarily by erythropterin pigment. Pterins are endogenously produced, though they are some of the most nitrogen-heavy pigments [28] [61]. It has been proposed that pterins are used as a nitrogenous waste product in insects, suggesting the pigment is 'cheap' [62]. However, plant herbivory often results in nitrogen limitation as an important factor in life history trade-offs [27]. Variation in pterin pigmentation between the sexes and between individuals could reflect differences in the ability to acquire dietary nitrogen, but variation in color can be found between individuals reared on the same host plant (personal observation). While the role of pterins as antioxidants in insects has not to our knowledge been studied,

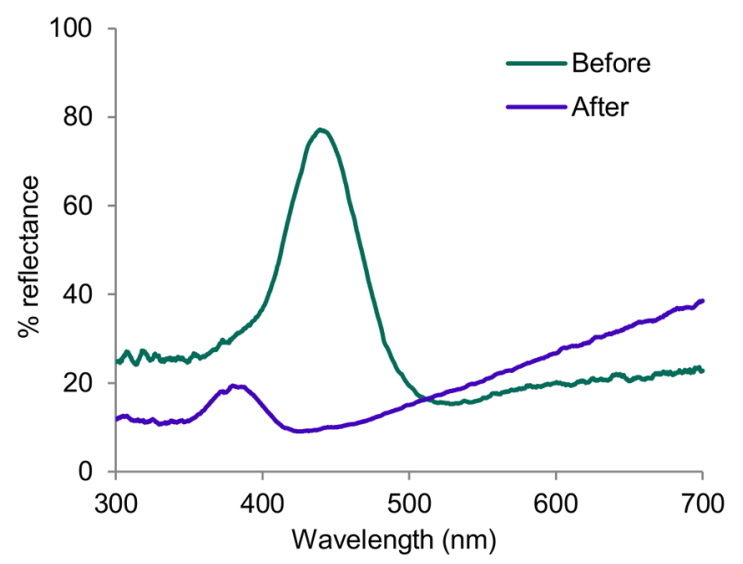

Figure 8. 'Before' and 'After' reflectance spectra after soaking bug in $\mathbf{3 0} \%$ hydrogen peroxide. 'Before' is the reflectance spectrum of the bug before soaking $24 \mathrm{~h}$ in $30 \% \mathrm{H}_{2} \mathrm{O}_{2}$, 'After' is the spectra taken after drying. Percent reflectance is against a Teflon white standard. Note the peak shifting to shorter wavelengths, reflective of the thinning of the layers in the multilayer system, and the monotonic increase at longer wavelengths.

doi:10.1371/journal.pone.0064082.g008 certain pterins are known to have antioxidant and immune modulating functions in vertebrates [63]. Given the prevalence of pterins as heteropteran pigments [47], we suggest that the use of erythropterin is as a phylogenetically conserved 'cheap' pigment for aposematic function, but whether it has protective function in Heteroptera requires further study. Furthermore, the average shift in reflectance between males and females suggests that the redorange pigment may also be playing a role in the creation of a sexual signal in addition to any aposematic function. Selective forces such as mate choice and predators may be selecting on the color pattern as a whole, so it is unsurprising that an element of the color pattern is likely contributing to multiple functions.

As a potentially 'derived' element of the color pattern, we are particularly interested in how the multilayer reflector system in the iridescent patches may act as an informative, honest sexual trait. It is more structurally complex than the pigmentary component of the signal. In addition to patch size and symmetry, signal quality depends on the regularity of both the dark and light layers, in both the vertical and horizontal dimensions. The precision required for this structure may be disturbed by developmental instability, making it a sensitive trait to display genetic quality and resistance to perturbation [19]. Pigmentary colors can also be sensitive to rearing conditions, and the reliance on melanin pigment as a major component may make the patches even more sensitive to environmental disturbance. For example, cuticular melanization can be upset by high temperatures in many taxa including Lepidoptera [64], Drosophila flies [26], and other Heteroptera [25]. This can help explain population differences, with high ambient temperatures suppressing the patches in tropical populations [34], and depending on the window of susceptibility, can also be contributing to intrapopulation variation, via seasonal or daily fluctuations in temperature [33].

Melanin-based signals may also be informative through tradeoffs with physiological uses for melanin and its precursors, in ways unique to invertebrates [65]. Tyrosine limitation may result in trade-offs with production of neurotransmitter dopamine or cuticle hardening agent sclerotin [23] [66]. Moreover, melanin and its precursors are utilized in the encapsulation response to endoparasites, a vital component of insect innate immunity, and cuticular coloration could trade off with immunocompetence [67] [68]. Conversely, enhanced melanic ornamentation could also be a result of greater systemic levels of melanin precursors or enzymes. In this way, the iridescent patches could act as an honest indicator of condition or immunocompetence [69]. Juvenile immune challenge can also influence adult expression of melanin coloration, rendering it an informative artefact of juvenile infection history [70]. 


\section{Variation and its effects on aposematism}

Despite the inherent variability in the iridescent patches, there may be aposematic benefit in iridescence. The 'complimentary' nature of green/blue and red/orange (e.g. little overlap in reflected wavelengths) enhances conspicuousness compared to a red/black pattern of comparable brightness [71]. The patches are also highly reflective and saturated, and the juxtaposition of bright and chromatic patches with a low brightness and chroma background (e.g. the red-orange base color) also enhances signal conspicuousness [71]. This brightness contrast may be especially important in aposematism against invertebrate predators such as praying mantids, whose hunting tactics may be more reliant on luminance contrast [72]. The downside of having iridescence is its variability, as there is increased predation risk for individuals that do not match the common morph [4] [73]. However, Ihalainen et al. [74] found evidence that being variable may in fact be beneficial to avoidance learning of moderately defended prey. Tectocoris diopthalmus' defensive capacity is moderate compared to other heteropterans [30] [75], and thus may benefit from this variation.

Conversely, variability in hue of orange pigmentation may have little influence on aposematic defense. Exnerová et al. [76] demonstrated that four bird species showed no difference in avoidance learning between red and orange morphs of the firebug Pyrrhocori apterus. Great Tits (Parus major) trained to avoid red artificial prey will generalize to avoid orange prey as well [77]. Lindstedt et al. [78] showed that while birds in the lab can discriminate between red and orange morphs and will preferentially attack orange, 'survival' of models in the field was equal

\section{References}

1. Ruxton GD, Sherratt TN, Speed MP (2005) Avoiding attack: the evolutionary ecology of crypsis, warning signals and mimicry: Oxford University Press, USA.

2. Thery M, Gomez D (2010) Insect Colours and Visual Appearance in the Eyes of Their Predators. In: Casas J, Simpson SJ, editors. Advances in Insect Physiology: Insect Integument and Colour. 267-353.

3. Stevens M, Ruxton GD (2012) Linking the evolution and form of warning coloration in nature. Proceedings of the Royal Society B: Biological Sciences 279: 417-426.

4. Mallet J, Barton NH (1989) Strong Natural Selection in a Warning-Color Hybrid Zone. Evolution 43: 421-431.

5. Greenwood JJD, Cotton PA, Wilson DM (1989) Frequency-dependent selection on aposematic prey: some experiments. Biological Journal of the Linnean Society 36: 213-226.

6. Roper TJ, Redston S (1987) Conspicuousness of distasteful prey affects the strength and durability of one-trial avoidance learning. Animal Behaviour 35: 739-747.

7. Gamberale-Stille G, Tullberg B (1999) Experienced chicks show biased avoidance of stronger signals: an experiment with natural colour variation in live aposematic prey. Evolutionary Ecology 13: 579-589.

8. Endler John A, Mappes J (2004) Predator Mixes and the Conspicuousness of Aposematic Signals. The American Naturalist 163: 532-547.

9. Speed MP, Ruxton GD (2007) How bright and how nasty: Explaining diversity in warning signal strength. Evolution 61: 623-635.

10. Blount JD, Speed MP, Ruxton GD, Stephens PA (2009) Warning displays may function as honest signals of toxicity. Proceedings of the Royal Society B: Biological Sciences 276: 871-877.

11. Lindstedt C, Talsma JHR, Ihalainen E, Lindström L, Mappes J (2010) Diet quality affects warning coloration indirectly: Excretion costs in a generalist herbivore. Evolution 64: 68-78.

12. Friman V-P, Lindstedt C, Hiltunen T, Laakso J, Mappes J (2009) Predation on multiple trophic levels shapes the evolution of pathogen virulence. PLoS One 4: e6761.

13. Maan ME, Cummings ME (2009) Sexual dimorphism and directional sexual selection on aposematic signals in a poison frog. Proceedings of the National Academy of Sciences 106: 19072-19077.

14. Kodric-Brown A, Brown JH (1984) Truth in advertising: the kinds of traits favored by sexual selection. American Naturalist: 309-323.

15. Nokelainen O, Hegna RH, Reudler JH, Lindstedt C, Mappes J (2012) Trade-off between warning signal efficacy and mating success in the wood tiger moth. Proceedings of the Royal Society B: Biological Sciences 279: 257-265. between morphs. With bugs of varying red and orange hues coexisting, birds may quickly learn to generalize. Variation in the size of iridescent patches has the potential for consequences on aposematism, as larger pattern elements increase avoidance in naïve chicks [79].

In conclusion, investigation into the mechanisms of color production has opened up a wealth of possible physiological and environmental interactions, and generated specific hypotheses to fuel future research directions. We have only used one species as a case study, but the commonplace chemical and microscopic techniques used here are easily applicable to many species. Variation in aposematism is a longstanding question in behavioral ecology, and a bottom-up approach of studying prey physiology is one way to help answer it.

\section{Acknowledgments}

We are grateful for the assistance of Debra Birch and Nicole Vella of the Microscopy Unit, Faculty of Science, Macquarie University, in preparing SEM/TEM sections, Kevin McGraw for valuable advice in regards to pigment analysis, Ron Rutowski for providing erythropterin standard, and our anonymous reviewers for their helpful feedback.

\section{Author Contributions}

Conceived and designed the experiments: SAF DJK MEH JK ZB. Performed the experiments: SAF JK ZB. Analyzed the data: SAF JK ZB. Contributed reagents/materials/analysis tools: DJK MEH ZB. Wrote the paper: SAF ZB.

16. Seago AE, Brady P, Vigneron JP, Schultz TD (2009) Gold bugs and beyond: a review of iridescence and structural colour mechanisms in beetles (Coleoptera). Journal of The Royal Society Interface 6 Suppl 2: S165-184.

17. Shawkey MD, Estes AM, Siefferman LM, Hill GE (2003) Nanostructure predicts intraspecific variation in ultraviolet-blue plumage colour. Proceedings of the Royal Society of London Series B: Biological Sciences 270: 1455-1460.

18. Kemp DJ, Rutowski RL (2007) Condition dependence, quantitative genetics, and the potential signal content of iridescent ultraviolet butterfly coloration. Evolution 61: 168-183.

19. Fitzpatrick S (1998) Colour schemes for birds: structural coloration and signals of quality in feathers. Annales Zoologici Fennici 35: 67-77.

20. Talloen W, Dyck HV, Lens L (2004) The cost of melanization: Butterfly wing coloration under environmental stress. Evolution 58: 360-366.

21. McGraw KJ, Mackillop EA, Dale J, Hauber ME (2002) Different colors reveal different information: how nutritional stress affects the expression of melaninand structurally based ornamental plumage. The Journal of Experimental Biology 205: 3747-3755.

22. Blount JD, Rowland HM, Drijfhout FP, Endler JA, Inger R, et al. (2012) How the ladybird got its spots: effects of resource limitation on the honesty of aposematic signals. Functional Ecology 26: 334-342.

23. Sugumaran M (2002) Comparative Biochemistry of Eumelanogenesis and the Protective Roles of Phenoloxidase and Melanin in Insects. Pigment Cell Research 15: 2-9.

24. Grether GF, Hudon J, Endler JA (2001) Carotenoid scarcity, synthetic pteridine pigments and the evolution of sexual coloration in guppies (Poecilia reticulata). Proceedings of the Royal Society of London Series B: Biological Sciences 268: 1245-1253.

25. Aldrich JR (1986) Seasonal variation of black pigmentation under the wings in a true bug (Hemiptera: Pentatomidae): a laboratory and field study. Proceedings of the Entomological Society of Washington 88: 409-421.

26. Gibert J M, F P, C S (2007) Phenotypic Plasticity in Drosophila Pigmentation Caused by Temperature Sensitivity of a Chromatin Regulator Network. PLoS Genetics 3.

27. Mattson WJ (1980) Herbivory in Relation to Plant Nitrogen Content. Annual Review of Ecology and Systematics 11: 119-161.

28. Kayser H (1985) Pigments. Comprehensive insect physiology, biochemistry and pharmacology 10: 367-415.

29. Cassis G, Vanags L (2006) Jewel Bugs of Australia (Insecta, Heteroptera, Scutelleridae). Denisia 19: 275-398.

30. Staddon B, Thorne M, Knight D (1987) The Scent Glands and Their Chemicals in the Aposematic Cotton Harlequin Bug, Tectocoris-Diophthalmus (Heteroptera, Scutelleridae). Australian Journal of Zoology 35: 227-234. 
31. Staples JK, Krall BS, Bartelt RJ, Whitman DW (2002) Chemical defense in the plant bug Lopidea robiniae (Uhler). Journal of Chemical Ecology 28: 601-615.

32. Noge K, Prudic K, Becerra J (2012) Defensive Roles of (E)-2-Alkenals and Related Compounds in Heteroptera. Journal of Chemical Ecology 38: 10501056 .

33. Ballard E, Holdaway FG (1926) The Life-history of Tectocoris lineola, F., and its Connection with Internal Boll Rots in Queensland. Bulletin of Entomological Research 16: 329-346.

34. Ballard E (1927) Some Insects associated with Cotton in Papua and the Mandated Territory of New Guinea. Bulletin of Entomological Research 17: 295-300.

35. Doucet SM, Meadows MG (2009) Iridescence: a functional perspective. Journal of The Royal Society Interface 6: S115-S132.

36. Rutowski RL, Nahm AC, Macedonia JM (2010) Iridescent hindwing patches in the Pipevine Swallowtail: differences in dorsal and ventral surfaces relate to signal function and context. Functional Ecology 24: 767-775.

37. Weidner VR, Hsia JJ (1981) Reflection properties of pressed polytetrafluoroethylene powder. JOSA 71: 856-861.

38. Xu M, Seago AE, Sutherland TD, Weisman S (2010) Dual Structural Color Mechanisms in a Scarab Beetle. Journal of Morphology 271: 1300-1305.

39. Reynods ES (1963) The use of lead citrate at high $\mathrm{pH}$ as an electron-opaque stain in electron microscopy. Journal of Cell Biology 17: 208-212.

40. McGraw KJ, Hudon J, Hill GE, Parker RS (2005) A simple and inexpensive chemical test for behavioral ecologists to determine the presence of carotenoid pigments in animal tissues. Behavioral Ecology and Sociobiology 57: 391-397.

41. Lindstedt C, Morehouse N, Pakkanen H, Casas J, Christides JP, et al. (2010) Characterizing the pigment composition of a variable warning signal of Parasemia plantaginis larvae. Functional Ecology 24: 759-766.

42. Fox DL (1976) Animal biochromes and structural colours: physical, chemical, distributional \& physiological features of coloured bodies in the animal world: Univ of California Press.

43. Wijnen B, Leertouwer H, Stavenga D (2007) Colors and pterin pigmentation of pierid butterfly wings. Journal of Insect Physiology 53: 1206-1217.

44. Han F, Huynh BH, Shi H, Lin B, Ma Y (1999) Pteridine analysis in urine by capillary electrophoresis using laser-induced fluorescence detection. Analytical Chemistry 71: 1265-1269.

45. Ito S, Nakanishi Y, Valenzuela RK, Brilliant MH, Kolbe L, et al. (2011) Usefulness of alkaline hydrogen peroxide oxidation to analyze eumelanin and pheomelanin in various tissue samples: application to chemical analysis of human hair melanins. Pigment cell \& melanoma research 24: 605-613.

46. Schultz T, Rankin M (1985) The ultrastructure of the epicuticular interference reflectors of tiger beetles (Cicindela). Journal of Experimental Biology 117: 87110

47. Merlini L, Nasini G (1966) Insect pigments - IV. Pteridines and colour in some Hemiptera. Journal of Insect Physiology 12: 123-127.

48. Melber C, Schmidt GH (1992) Identification of Fluorescent Compounds in Certain Species of Dysdercus and Some of Their Mutants (Heteroptera, Pyrrhocoridae). Comparative Biochemistry and Physiology B-Biochemistry \& Molecular Biology 101: 115-133.

49. Bel Y, Porcar M, Socha R, Němec V, Ferré J (1997) Analysis of pteridines in Pyrrhocoris apterus (L.) (Heteroptera, Pyrrhocoridae) during development and in body-color mutants. Archives of Insect Biochemistry and Physiology 34: 8398.

50. Niva CC, Takeda M (2002) Color changes in Halyomorpha brevis (Heteroptera : Pentatomidae) correlated with distribution of pteridines: regulation by environmental and physiological factors. Comparative Biochemistry and Physiology B-Biochemistry \& Molecular Biology 132: 653-660.

51. Miyamoto K, Kosaku A (2002) Cuticular Microstructures and Their Relationship to Structural Color in the Shieldbug Poecilocoris lewisi. Forma 17: 155-167.

52. Vigneron JP, Ouedraogo M, Colomer JF, Rassart M (2009) Spectral sideband produced by a hemispherical concave multilayer on the African shield-bug Calidea panaethiopica (Scutelleridae). Physical Review E 79.

53. Schultz T, Rankin M (1985) Developmental changes in the interference reflectors and colorations of tiger beetles (Cicindela). Journal of Experimental Biology 117: 111-117.

54. Stavenga DG, Wilts BD, Leertouwer HL, Hariyama T (2011) Polarized iridescence of the multilayered elytra of the Japanese jewel beetle, Chrysochroa fulgidissima. Philosophical Transactions of the Royal Society B: Biological Sciences 366: 709-723.
55. Fitzstephens DM, Getty T (2000) Colour, fat and social status in male damselflies, Calopteryx maculata. Animal Behaviour 60: 851-855.

56. Kroiss J, Strohm E, Vandenbem C, Vigneron J-P (2009) An epicuticular multilayer reflector generates the iridescent coloration in chrysidid wasps (Hymenoptera, Chrysididae). Naturwissenschaften 96: 983-986.

57. Schultz TD, Bernard GD (1989) Pointillistic mixing of interference colours in cryptic tiger beetles. Nature 337: 72-73.

58. Durrer H, Villiger W (1972) Schillerfarben von Euchroma gigantea (L.): Coleoptera: Buprestidae): Elektronenmikroskopische untersuchung der elytra. International Journal of Insect Morphology and Embryology 1: 233-240.

59. Noyes JA, Vukusic P, Hooper IR (2007) Experimental method for reliably establishing the refractive index of buprestid beetle exocuticle. Optics express 15: 4351-4358.

60. Sun MX, Liang AP, Zheng YM, Watson GS, Watson JA (2011) A study of the anti-reflection efficiency of natural nano-arrays of varying sizes. Bioinspiration \& Biomimetics 6 .

61. McGraw KJ, Toomey MB, Nolan PM, Morehouse NI, Massaro M, et al. (2007) A description of unique fluorescent yellow pigments in penguin feathers. Pigment Cell Research 20: 301-304.

62. Harmsen R (1966) The excretory role of pteridines in insects. Journal of Experimental Biology 45: 1-13.

63. McGraw KJ (2005) The antioxidant function of many animal pigments: are there consistent health benefits of sexually selected colourants? Animal Behaviour 69: 757-764.

64. Hazel WN (2002) The environmental and genetic control of seasonal polyphenism in larval color and its adaptive significance in a swallowtail butterfly. Evolution 56: 342-348.

65. Stoehr A (2006) Costly melanin ornaments: the importance of taxon? Functional Ecology 20: 276-281.

66. Sugumaran M (1998) Unified Mechanism for Sclerotization of Insect Cuticle. In: Evans PD, editor. Advances in Insect Physiology: Academic Press. 229-334.

67. Siva-Jothy MT (2000) A mechanistic link between parasite resistance and expression of a sexually selected trait in a damselfly. Proceedings of the Royal Society B: Biological Sciences 267: 2523-2527.

68. González-Santoyo I, Córdoba-Aguilar A (2012) Phenoloxidase: a key component of the insect immune system. Entomologia Experimentalis et Applicata 142: $1-16$.

69. Rantala MJ, Koskimaki J, Taskinen J, Tynkkynen K, Suhonen J (2000) Immunocompetence, developmental stability and wingspot size in the damselfly Calopteryx splendens L. Proceedings of the Royal Society B: Biological Sciences 267: 2453-2457.

70. Jacot A, Scheuber H, Kurtz J, Brinkhof MWG (2005) Juvenile immune status affects the expression of a sexually selected trait in field crickets. Journal of Evolutionary Biology 18: 1060-1068.

71. Endler JA (1992) Signals, Signal Conditions, and the Direction of Evolution. The American Naturalist 139: S125-S153.

72. Prudic KL, Skemp AK, Papaj DR (2007) Aposematic coloration, luminance contrast, and the benefits of conspicuousness. Behavioral Ecology 18: 41-46.

73. Lindström L, Alatalo RV, Lyytinen A, Mappes J (2001) Strong antiapostatic selection against novel rare aposematic prey. Proceedings of the National Academy of Sciences 98: 9181-9184.

74. Ihalainen E, Lindstrom L, Mappes J (2007) Investigating Müllerian mimicry: predator learning and variation in prey defences. Journal of Evolutionary Biology 20: 780-791.

75. Schaefer CW (1972) Degree of metathoracic scent-gland development in the trichophorous Heteroptera (Hemiptera). Annals of the Entomological Society of America 65: 810-821.

76. Exnerová A, Svádová K, Štys P, Barcalová S, Landová E, et al. (2006) Importance of colour in the reaction of passerine predators to aposematic prey: Experiments with mutants of Pyrrhocoris apterus (Heteroptera). Biological Journal of the Linnean Society 88: 143-153.

77. Ham AD, Ihalainen E, Lindström L, Mappes J (2006) Does colour matter? The importance of colour in avoidance learning, memorability and generalisation. Behavioral Ecology and Sociobiology 60: 482-491.

78. Lindstedt C, Eager H, Ihalainen E, Kahilainen A, Stevens M, et al. (2011) Direction and strength of selection by predators for the color of the aposematic wood tiger moth. Behavioral Ecology 22: 580-587.

79. Forsman A, Merilaita S (1999) Fearful symmetry: pattern size and asymmetry affects aposematic signal efficacy. Evolutionary Ecology 13: 131-140. 